\title{
AZORÍN EN CHINA ${ }^{1}$
}

\author{
MIN SUN \\ Universidad de Xiamen \\ mayo1989@live.cn
}

ORCID: 0000-0002-1186-2752

\section{RESUMEN}

Este artículo tiene como objetivo estudiar la recepción de la obra de Azorín en China. Para ello, se consideran las traducciones realizadas de sus ensayos y cuentos, así como las opiniones que aportaron algunos críticos literarios chinos, vertidas en numerosas reseñas y artículos, tanto en el siglo XX como en el XXI. Particularmente, se revisan las traducciones realizadas por Dai Wangshu, Xu Xiacun, Bian Zhilin, entre otros. Con ello se pretende explorar la influencia que ejerció Azorín en algunos escritores chinos modernos, tal como ocurre con el caso de Wang Zengqi, y, más allá, en la influencia que tuvo para la propia construcción de la literatura china moderna.

PALABRAS CLAVE: Azorín, China, traducción, influencias, literatura comparada.

\section{AZORÍN IN CHINA}

\section{ABSTRACT}

This article aims to study the reception of Azorín's work in China. For this, we will review his Chinese translation works, as well as the opinions contributed by some Chinese literary critics, expressed in numerous reviews and articles, both in the 20th and 21st centuries. In particular, the translations made by Dai Wangshu, Xu Xiacun, Bian Zhilin, among others, are reviewed. This is intended to explore the influence that Azorín exerted on some modern Chinese writers, such as Wang Zengqi, and also on the influence he had for the construction of modern Chinese literature itself.

KEYWORDS: Azorín, China, translation, influence, Comparative Literature.

\section{INTRODUCCIÓN}

El tema de la influencia cultural y sus efectos es considerado una cuestión fundamental en el ámbito de la literatura comparada, sobre todo desde las reflexiones que aportaba la escuela francesa. Las relaciones literarias entre China y España nos resultan ciertamente distantes, ya que ambas han permanecido durante buena parte de su historia ajenas a cualquier tipo de influencia mutua. Aunque la relación de dependencia es inevitable entre culturas, antes del siglo XX no se realiza una verdadera recepción de la literatura española en China. No

\footnotetext{
${ }^{1}$ Esta investigación forma parte del proyecto «Las relaciones literarias entre China y España (1915-1940)» (Proyecto de Ciencias Sociales de la Provincia de Fujian, China, referencia FJ2021C049), también es apoyada por los Fondos de Investigación Fundamental para las Universidades Centrales (China), con número de referencia de ZK1096.
} 
obstante, cuando se produjo, despertó un interés particular en el país asiático, considerándose el primer auge de recepción allá por la década de los años 30.

No cabe duda de que uno de los autores españoles más traducidos en la primera mitad del siglo XX, que acabaría influyendo ampliamente en la construcción de la literatura china moderna, fue Azorín, a pesar de que era Pío Baroja el autor que resultaba más conocido fuera de España. ${ }^{2}$

Entre los autores introducidos a China en aquel momento destacaban Unamuno, Valle-Inclán, Galdós, Blasco Ibáñez, Pérez de Ayala y García Lorca, además de otros poetas de la generación del 36, como Alberti y Aleixandre. Por supuesto, en el horizonte de la traducción de obras en español y su auge se encontraba el Don Quijote de Cervantes, ya que de 1922 data la primera traducción de la obra al chino mandarín a través de una edición de Lin Shu y Chen Jialin El caballero mágico (《魔侠传》) ${ }^{3}$. A parte de Cervantes, todos eran autores coetáneos, mostrándose una casi inmediata recepción de la literatura española en China. Los autores de la generación del 98 se configuran como los más admirados y leídos, pero, sobre todo, se aprecia una importante admiración por Azorín, ${ }^{4}$ destacando su gran talento artístico por parte de los eruditos literarios chinos. Prácticamente, una veintena de reconocidos autores chinos, en mayor o menor medida, dejaron constancia de la admiración e influencia que la lectura de las obras de Azorín ${ }^{5}$ les había causado, tales como Dai Wangshu (戴望 舒), Wang Zengqi (汪曾祺), Shi Tuo (师陀) y Mu Shiying (穆时英).

\footnotetext{
2 En el capítulo «Los extranjeros» de Madrid (2017: § 42, 152 y ss.), Azorín manifestaba también que era Pío Baroja el autor de mayor proyección internacional mostraba: «El primer escritor del 98 de quien se ha hablado seria y extensamente en el extranjero es Baroja». Así lo afirmaba también Han Juretschke en su «La recepción de la generación del 98 en Europa en la primera mitad de nuestro siglo» (1998: 54): «Los que más se han leído y más se comentan con notable atención son Valle Inclán y Pío Baroja».

${ }^{3}$ Ese mismo año, Zhou Zuoren (周作人) publica un artículo titulado «La biografía del caballero mágico» en el periódico Periódico matutino (《晨报》 1920, 4 de septiembre), comentando la importancia del libro (lo compara en importancia con el Hamlet de Shakespeare), concluyendo que don Quijote es la encarnación de lo ideal, mientras que Sancho lo es de la experiencia. Para Zhou, el libro era representante de la propia época que le había tocado vivir, ya que se identificaba a sí mismo como idealista, todo ello en el contexto cultural del Cuatro de Mayo (Qian Liqun 1994: 99-100).

${ }^{4}$ El sinólogo Carles Prado-Fonts también anotó este hecho en «El nacimiento de la literatura moderna»: «Curiosamente, Azorín, uno de los autores más destacados de esta generación (98), llegó a ser traducido al chino con cierta asiduidad: durante los años treinta y gracias a los jóvenes escritores modernistas de Shanghái» (2008: 120).

${ }^{5}$ Sang Nong (2003: 3) llega a nombrar diecinueve escritores chinos admiradores de Azorín, incluidos Dai Wangshu (戴望舒 1905-1950), Xu Xiacun (徐霞村 1907-1986), Zhou Zuoren (周作人 1885-1967), Tang Tao (唐㢷 1913-1992), Shi Tuo (师陀 1910-1988), Fu Lei (傅雷 1908-1966), Bian Zhilin (市之琳 1910-2000), He Qifang (何其芳 1912-1977), Li Guangtian (李广田 1906-1968), Feng Zhi (冯至 1905-1993), Shen Congwen (沈从文 1902-1988), Lin Huiyin (林徽因 1904-1955), Li Jianwu (李健吾 1906-1982)，Jin Kemu (金克木 1912-2000), Fang Jing (方敬 1914-1996), Nan Xing (南星 1910-1996), Ceng Zhuo (曾卓 1922-2002), Tang Shi (唐湜 1920-2005) y Wang Zengqi (汪曾祺 1920-1997), todos ellos fueron intelectuales destacados en su época.
} 
La difusión de Azorín en China, sin duda, es un tema de investigación llamativo del ámbito de la historia literaria moderna china y de la literatura comparada entre la literatura china y la española. ¿Por qué Azorín fue tan admirado en China, sobrepasando con mucho a otros autores españoles cogeneracioncitas que también habían sido conocidos por aquella época a la par en China? ¿Qué obras suyas fueron las más traducidas? ¿Qué influencia ejerció? Estas son algunas de las cuestiones que se plantean a lo largo del presente artículo.

\section{LA DIFUSIÓN DE LA LITERATURA ESPAÑOLA EN CHINA DURANTE LA PRIMERA MITAD DEL S. XX}

La difusión cultural y literaria se manifiesta, por lo general, a través de dos formas: la directa y la indirecta. La primera ocurre cuando algunos elementos del emisor han sido prestados directamente al receptor; la segunda es por vía de los intermediarios, a través de los traductores o de los críticos (Gil-Albarellos 2006: 80). La influencia es favorecida mediante el trabajo que realizan traductores, críticos, editores y revistas. Así pues, «viajes, libros de viajes, artículos de periódicos, revistas consideradas en su acción de conjunto, traducciones, diccionarios, compañías de actores ambulantes; y también la enseñanza de idiomas, los críticos, los cenáculos y otros componentes que son como las mallas de una gran red literaria internacional» (Guillén 2005: 73). Estas son, entre otras, las consideraciones que deben de tener en cuenta los comparatistas.

En cuanto a las influencias culturales, la accesibilidad de una literatura extranjera en China se vincula estrechamente con el clima político, social y cultural de la época en cuestión en la que se produce: «La relación entre literatura y política es una constante en la historia de China» (Fisac 2017: 47). Este fenómeno queda más patente desde el siglo XIX, ya que la decadencia del poder político y económico de China acabarían por estimular y desplegar una serie de reformas que procedían mayoritariamente de Occidente. En el ámbito de la literatura, este factor produjo una gran repercusión a través del movimiento de la Nueva Cultura, que supuso una ruptura con el tradicionalismo y cambió el panorama literario chino. Se introdujeron textos extranjeros de una manera masiva, ${ }^{6}$ y la literatura española se configuró como una de las más atrayentes, ya que este interés se debía a la consideración de que eran naciones que compartían una misma afinidad de destino, puesto que España sufrió una decaída sustancial desde su pasado de gran potencia hegemónica de Europa. Esta decadencia quedó representada fundamentalmente por la crisis del 1898 y, más tarde, por el estallido de la Guerra Civil de 1936 a 1939, que tuvo una gran repercusión internacional. En 1917, Lu Xun (鲁迅 1881-1936) declaraba que la literatura

\footnotetext{
${ }^{6}$ Se sostenía la idea de que lo extranjero representaba lo nuevo y lo chino, lo anticuado.
} 
española se encontraba en el grupo de «las nacionalidades débiles y pequeñas», lo que, curiosamente, influenció bastante para su llegada al país asiático. ${ }^{7}$

Por aquellos años, se dieron a conocer los nombres de Baroja, Valle-Inclán, Azorín, Unamuno, Galdós, Pardo Bazán, Palacio-Valdés, Clarín, Maeztu, Valera, Alarcón, Ayala, Benavente, Echegaray, Azorín, etc. Como es sabido, estos autores evocaron un gran interés por el pasado y el funesto destino que mostró España, tema que permitió una reflexión profunda y grandes rasgos de creatividad, ya que con su labor se pretendía, en cierto sentido, salvar a España de la crisis de valores tradicionales que la habían encumbrado en el pasado. Ese ambiente de efervescencia del espíritu nacional puede ser una posible explicación del interés de la China de aquella época, ya que igualmente era consciente de su decadencia.

Por lo tanto, la entrada de la literatura española en China llevó aparejada consigo ciertos matices políticos. En las primeras dos décadas del XX, la turbulenta política interior y exterior de China produjo un sentimiento sobre la vida muy parecida a la que mostraron los españoles noventayochistas: ${ }^{8}$

En la escuela del 98 había dos palabras fundamentales, dos palabras representativas y compendiadoras del espíritu de tal tendencia. Esas dos palabras eran: frivolidad, España. (Azorín 2017: 104)

Los intelectuales chinos del momento toman la literatura como instrumento para llevar a cabo una revolución de conciencias $\mathrm{y}$, consecuentemente, reivindicar el carácter nacional. Por tanto, esta primera fase de recepción está marcada por la acogida de ideas y pensamientos, en lugar de centrar su interés en la estimación del estilo literario.

Además de Azorín, las figuras de Blasco Ibáñez y Pío Baroja ${ }^{9}$ sobresalen en el mundo de los lectores chinos. Como comentamos, no tanto por su creatividad, sino, más bien, por su compromiso social, valiéndose de un enfático realismo. En el caso de Blasco Ibáñez, antes de su llegada a China en 1923, ya se conocía entre los lectores chinos. Ibáñez tuvo la suerte de contar con la ayuda inestimable de los autores chinos más destacados del panorama cultural de principios de siglo:

${ }^{7}$ El término «nacionalidades débiles y pequeñas» fue propuesto durante el movimiento del Cuatro de Mayo y se refería a los países considerados secundarios en el panorama internacional actual de aquella época, pero que habían mostrado un pasado glorioso, tales como Polonia, Dinamarca, Suecia, etc. En este grupo, en su consideración, entraría España. Hubo una tendencia a traducir las literaturas de estos países durante la década de los veinte y treinta en China, además de introducir las literaturas de potencias fuertes europeas, así como de la siempre influyente literatura rusa y japonesa.

${ }^{8}$ Carles Prado-Fonts (2008: 120) afirma lo mismo: «En cierta medida, la situación intelectual de China de finales del siglo XIX mantiene muchas similitudes con la generación del 98 española».

9 Pío Baroja, a pesar de que nunca hubo viajado a China, estampó unas impresiones sobre imágenes chinas en varios libros suyos como, por ejemplo, en su Yan-Si-Pao o La esvástica de oro (1928), y también en La estrella del capitán Chimista (1930). Se había dado a conocer en China a este autor vasco por las críticas literarias, como las de Lu Xun y las de Shen Yanbing (沈雁冰), la de Xu Xiacun, etc., a lo largo de los años 20 y 30. 
los hermanos Zhou Zuoren (周作人) y Luxun (鲁迅), que consiguieron estimular la difusión de la literatura española en China. Luxun, autor que contribuyó a la traducción de más de cuatrocientos títulos de literatura extranjera en China entre 1917 y 1927, fue un gran admirador del Don Quijote (Fisac 2017: 50). En varias ocasiones manifestó sus conocimientos sobre literatura española. Por ejemplo, en 1928, recordó que Blasco Ibáñez y Pío Baroja eran los autores más importantes de España. Posteriormente, tradujo al chino los cuentos del autor vasco, Vidas sombrías, desde una versión en japonés, traducida bajo el título de Canciones pastorales de los montañeses (《山民牧唱》). ${ }^{10}$ Zhou Zuoren, por su parte, según comentó en su artículo «La ciudad antigua de España» (《西班牙的古城》) (1930), - con dedicación a Azorín—, comenta que había leído la biografía de Cervantes, escrita por un autor inglés, La vida de don Quijote y Sancho de Miguel Unamuno y Los cuatro jinetes del Apocalipsis de Blasco Ibáñez. También confesó que era gran admirador de Azorín después de leer La novia de Cervantes (《塞万提斯的未婚妻》) (1930), traducida por Dai Wangshu y Xu Xiacun.

La difusión de la literatura española, por lo tanto, se encontraba favorecida por diversos estímulos, especialmente por los críticos y traductores, quienes ejercieron un gran papel en el intercambio de ideas. Cabe decir que la recepción en esta época fue más bien indirecta, en el sentido de que la mayoría de las traducciones se realizaron a través de versiones en francés o en inglés, incluso en japonés, debido a la falta de conocimientos del español por aquel entonces en China. El éxito de la buena difusión y acogida podría provenir del hecho de que los primeros traductores fueron ellos mismos autores eminentes en su época, por su propia fama, y por el gran conocimiento y dominio que ejercían de la lengua china.

\section{LA INTROdUCCIÓN DE Azorín EN CHINA}

Las traducciones de las obras de Azorín al chino se circunscribían a una treintena de ensayos, tales como su discurso de ingreso a la Real Academia Española, recogido bajo el título Una hora de España (Entre 1560 y 1590). A pesar de las pocas obras traducidas, - si la comparamos, por ejemplo, con la cantidad de obras de Blasco Ibáñez-, Azorín es, sin duda, uno de los autores españoles modernos más influyentes en China, si no el que más. Los nombres de tres traductores chinos coetáneos destacan en esta tarea: Xu Xiacun (徐霞村), Dai Wangshu (戴望舒) ${ }^{11} \mathrm{y}$ Bian Zhilin (市之琳), entre otros. Además de su gran cometido como traductores,

10 Todas las traducciones de títulos de libros o artículos chinos al español son mías.

11 Dai Wangshu comenzó a estudiar francés desde 1925 en la Universidad Zhendan (Universidad Aurora, fundada por los jesuitas franceses), teniendo la oportunidad de leer obras de Víctor Hugo, Camus, etc., lo que le llevó a la tarea de su traducción al chino. En noviembre de 1932, se marchó a Francia, donde tuvo grandes relaciones con miembros del simbolismo francés. Pero la inquietud de Dai por España le hizo viajar hasta allí y aprender español. 
el primero fue un gran crítico literario y ensayista, y los otros dos llegaron a ser eminentes poetas.

Xu Xiacun, ${ }^{12}$ al que se puede considerar como el primer traductor de Azorín, se interesó mucho por la literatura española moderna y publicó en la revista modernista juvenil Tren sin rieles (《无轨列车》) ${ }^{13}$ en diciembre de 1928 (número 8), el breve relato del alicantino titulado «Los toros», plasmando con ello un estereotipo de la cultura ibérica para el lector chino. Debido al éxito cosechado, al año siguiente, en 1929, lanzó una recopilación de ensayos contemporáneos españoles titulada también Los toros (《斗牛》), de la editorial Chunchao (春潮出版社) (Shanghái 1929), en la que se incluían cuatro obras: aparte de «Los toros», también se incluían relatos de Unamuno, Rubén Darío y Pedro Antonio de Alarcón. En julio del mismo año, en la revista Ficción Mensual (《小说 月报》) publicó un texto de crítica literaria: «La literatura española de los últimos 20 años» (《二十年来的西班牙文学》), donde valoró positivamente a Azorín por su gran capacidad literaria. Este texto fue incluido en su Panorama de la literatura moderna de Europa Meridional (《现代南欧文学概观》) de 1930, que abarca en sí una introducción a la literatura italiana, española y griega de la época moderna, donde reitera su admiración por Azorín, por lo que ofrece un estudio pormenorizado sobre él con el subtítulo de «Un ensayista sin precedentes: Azorín» (《一位绝世的散文家: 阿左林》), configurando así uno de los primeros estudios críticos sobre el autor español.

El otro gran traductor de Azorín fue Dai Wangshu. En octubre de 1929, en el primer volumen (número 2) de la revista Nuevo arte, Dai Wangshu dio a conocer dos ensayos suyos: «El apañador» $\mathrm{y}$ «El melcochero». Un año después, en 1930, Dai colaboró con Xu Xiacun para la publicación del libro La novia de Cervantes (《塞万提斯的未婚妻》, editorial Shenzhou Guoguang (神州国光出版社), donde reúne un total de 26 ensayos provenientes de Los pueblos (1905) y España. Hombres y paisajes (1909). Según manifiesta Dai en el prólogo, la traducción está basada en la versión francesa Espagne (1929) de G. Pillement. Como traducción indirecta, no está exenta de erratas, pues algunas frases se desvían del significado del texto original, pero lo cierto es que el estilo de la traducción en chino es imponente y muy poético, ligado al estilo de la época. Aunque la traducción ideal no exista, gracias a estos dos factores concomitantes, la traducción al chino de la obra de Azorín ha resultado en un éxito duradero. El libro acabó teniendo una divulgación rápida. Particularmente, lo compró Zhou Zuoren (周作人) tras ser recomendado por Feng Zhi (冯至) ${ }^{14}$ adquiriendo también Panorama de la literatura

\footnotetext{
${ }^{12}$ Xu Xiacun (1907-1986), escritor y traductor de numerosas obras literarias, buen conocedor del francés y del inglés, contrajo un gran interés por la literatura francesa y por la literatura del sur de Europa a través de su breve estancia en Francia entre 1927 y 1928.

${ }^{13}$ Fue una de las tres revistas más importantes del área del modernismo chino. Las otras dos revistas eran Nuevo arte (《新文艺》) (1929-1930) y Les Contemporains (《现代》) (1932-1935).

${ }^{14}$ Feng Zhi (冯至 1905-1993) fue un escritor, poeta y crítico literario muy reconocido. Lu Xun le atribuyó el título de «poeta lírico más eminente de China».
} 
moderna de Europa Meridional de Xu Xiacun, con el precio desorbitante para la época de casi un yuan. Los leyó con gran avidez y entusiasmo, llegando a exclamar «¿Cuándo podré escribir yo unos relatos tan eminentes?» (Zhou Zuoren 2002: 116)..$^{15}$

El libro despertó de inmediato el gran interés entre otros intelectuales muy importantes del país, por ejemplo, entre el consagrado poeta Bian Zhilin, quien a partir de entonces comenzó a estudiar español y que en $1943^{16}$ presentó otra versión de la obra con el título de Compilación de relatos de Azorín (《阿左林小集》), publicada por la editorial Libros del Pueblo (人民图书出版社). Dicho libro se reeditó en 1982, junto con otras traducciones realizadas por él, en su Compilaciones de la ventana oeste (《西窗集》). Según manifiesta en el prólogo, acudió en su mayor parte a la versión francesa y la inglesa para completar este trabajo, además de contar con la ayuda de Dai para la lectura del texto original en el español (Bian 1982: 2). Es una antología de textos seleccionados desde la obra Antonio Azorín (que cuenta con nueve relatos, basados en la versión inglesa publicada en la revista The Dial), de España: hombres y paisajes (un relato, basado en la versión inglesa publicada en la revista The Dial), Don Juan (nueve relatos, basados en una versión inglesa), Félix Vargas (dos relatos, según una versión francesa), Blanco en azul (siete relatos, basados en una versión inglesa).

Aunque no se pueda considerar a Azorín un nombre de primera fila entre todos los escritores extranjeros traducidos e introducidos en la China moderna, como Cervantes o Shakespeare, aunque su fama no alcance a Víctor Hugo o a Marcel Proust, sin embargo, Azorín asume un encanto artístico duradero e inolvidable para algunos escritores chinos. En 1980, cuando ya habían pasado más de cincuenta años desde la primera publicación de la traducción de Xu y Dai, el escritor Tang Tao (唐㢱) en su artículo «Azorín» confesaba que muchos amigos se interesaban por ese libro ya descatalogado. Como él poseía uno, finalmente, se lo acabó regalando al gran traductor chino Fu Lei (傅雷), historia que también recordaba Sang Nong (桑农), editor de La novia de Cervantes (en la versión de 2013). Dos años después, en 1982, la editorial Pueblo de Fujian volvió a publicarlo con el título de Paisaje de España (《西班牙小景》, revisado por Xu Xiacun).

La tercera gran traducción de la obra de Azorín vería la luz en octubre de 1988, fruto de la labor de dos hispanistas, el matrimonio Xu Cenghui (徐曾惠) y Fan Ruihua (樊瑞华). Se tituló de El jardín castellano (《卡斯蒂利亚的花园》), publicada por la editorial Escritores (作家出版社) y consta de 51 relatos correspondientes a Los pueblos; España: hombres y paisajes; y Castilla. Se trata de una traducción directa del español al chino. No obstante, parece que no produjo amplias repercusiones, salvo en algunos coleccionistas de Azorín, tal como

\footnotetext{
${ }^{15}$ Por ejemplo, leyó este ensayo Bian Zhilin (2002: 4).

${ }^{16}$ En su memoria «Aquella noche traduciendo Azorín»(《译阿左林小品之夜》), confesó que su traducción de Azorín empezó por lo menos desde 1934 en diversas publicaciones (Bian Zhilin 2002: 4).
} 
afirma Sang Nong (2018) ${ }^{17}$ en su artículo «Encontrar a Azorín de nuevo», publicado después de la salida de una nueva traducción realizada por Lin Yian (2018), que comentaremos después.

También destaca la traducción del 2013 editada por Sang Nong y publicada por la editorial asiática Joint Publishing Company (三联书店). Sang Nong, admirador de Dai Wangshu, la compuso como homenaje al propio Dai, por lo que recoge en ella únicamente los relatos traducidos por él. El libro se divide en tres partes: la primera abarca 16 textos sacados de la versión de 《西班牙小景》 (Paisaje de España, 1982) - y de la segunda edición de La novia de Cervantes (1930), estos relatos corresponden a los libros Los pueblos y España: hombres y paisajes-; la segunda parte se compone de 18 textos de Una hora de España ${ }^{18}$ y la tercera de 8 relatos de Los pueblos, que fueron recopilados de los periódicos en los que publicó Dai Wangshu (Sang Nong 2013: 1). ${ }^{19}$

La traducción más actual de Azorín data de 2018 y fue realizada por el hispanista Lin Yian (林一安). ${ }^{20}$ Se trata de una traducción directa del español al chino, titulada La famosa decadencia: una selección de Azorín (《著名的衰落: 阿左林 小品集》). Está considerada como la versión más completa que haya de las obras traducidas al chino de Azorín hasta hoy día. Incluye cuatro libros completos del autor: Los pueblos; España: hombres y paisajes; Castilla; y Una hora de España, todos

\footnotetext{
${ }^{17}$ Sang Nong (2018, 21 de marzo), 《又见阿索林》/ «Encontrar a Azorín de nuevo». 中华读书报 I Diario Lectura Zhonghua. Véase en: <https://epaper.gmw.cn/zhdsb/html/201803/21/nw.D110000zhdsb_20180321_2-11.htm?div=-1> (fecha de consulta: 30 de agosto de 2021).

${ }_{18}$ Dai mantuvo correspondencia con Azorín, le escribió para pedir su permiso para la traducción de Una hora de España, advirtiéndole que podía realizarla sin condiciones. Parte de las traducciones de este libro vería la luz en el primer y segundo volumen de la revista Les Contemporains (《现代》en 1932) (Dai 1999: 463).

${ }^{19}$ El periódico español Información plasmó este hecho en su diario del 14 de abril de 2013 con el artículo «Azorín viaja a China», donde detalla que «las obras Castilla y Los pueblos del escritor monovero despiertan el interés de una editorial del país asiático y se traducen por primera vez al mandarín». Esta noticia es incierta por dos razones: no especifica que tal traducción es una recopilación de todas las traducciones realizadas por Dai Wangshu de Azorín a lo largo de su vida (Dai murió en 1950) desde la década de los 30; la selección no incluye Castilla, sino Los pueblos; España: hombres y paisajes; y Una hora de España. Curiosamente, como dato de interés, dos años después se repite esta imprecisión en el periódico valenciano Levante (26 de marzo de 2015), pero se constata el interés que muestra Azorín en China: «A un escritor se le renueva y revaloriza por sus nuevas ediciones, estudios críticos y, cómo no, por sus traducciones. Unas premisas que, si atendemos al caso de Azorín, el escritor y periodista de Monóvar, se cumplen a todas luces. Tanto es así que, hace apenas unas semanas, la editorial asiática Joint Publishing Company, una de las más importantes del imperio cultural chino, ha publicado una obra con distintos pasajes del legado literario de José Martínez Ruiz como Los pueblos (1905), España. Hombres y paisajes (1909) y Una hora de España (1924) traducidos por vez primera al mandarín» (Payá 2015).

${ }^{20}$ Lin Yian (1936) es uno de los grandes investigadores en literatura hispanoamericana y fue uno de los primeros estudiantes de español en China, graduándose en la facultad de español en la Universidad de Lenguas Extranjeras de Pekín en 1959. Confesó que se enamoró del español por la lectura de Los pueblos de Azorín, que se encontró en su versión original en español en la biblioteca de su universidad (véase su obra Azorín 2018: 1).
} 
organizados según los libros originales. El tiempo tasará la calidad e influencia de esta traducción, pero en principio parece de una gran calidad. No cabe duda de que Azorín se revive en China por medio de este tipo de traducciones y las reiteradas ediciones. Tal como señala Benjamín (1996: 337) en su famoso artículo «La tarea del traductor»:

La historia de las grandes obras de arte comprende a su ascendencia, desde sus orígenes; a su creación en la época del artista y al período de la prolongación, en un principio perpetua, de su vida, durante las generaciones posteriores. (Benjamín 1996: 337)

\title{
4. LAS INFLUENCIAS DE LA NOVIA DE CERVANTES (1930) TRADUCIDA POR DAI WANSHU Y COMPILACIÓN DE RELATOS DE AZORÍN (1942) POR BIAN ZHILIN
}

Las distintas reflexiones teóricas sobre las limitaciones e imposibilidades que muestra la traducción han sido constantes en la traductología. La tarea de una traducción satisfactoria es prácticamente imposible. Sea como sea, es indudable que el producto de la traducción literaria posee una efectividad social y cultural. A nuestro parecer, las traducciones de Dai Wangshu, Xu Xiacun y la de Bian Zhilin, a pesar de sus carencias - traducción indirecta la mayor parte de las veces, incursión en errores de significado algunas veces_, resultan indudablemente las más apreciadas. Según comentario de Sang Nong:21

\begin{abstract}
Azorín fue un escritor español que escribía en español y traducirle directamente del español debería ser una tarea que buscara fielmente la versión original. Sin embargo, para los lectores, la lealtad es importante, pero no es lo más importante. La novia de Cervantes (《塞万提斯的未婚妻》) (1930) y Compilación de relatos de Azorín (《阿左林小集》) (1943) son ambas traducciones indirectas y seguramente llena de distorsiones, pero esto no afecta al gusto de los lectores comunes y a los escritores famosos (como Zhou Zuoren, Wang Zengqi, etc.), esto no afecta para haberse convertido en clásicos de la historia de la literatura traducida. Por el contrario, el libro El jardín castellano (《卡斯蒂利亚的花园》) (1988) fue traducido fielmente del español original y apenas tuvo repercusión en su momento, no dejó huella hasta más tarde, cuando se hicieron recopilaciones de las traducciones de Azorín. El libro $\mathrm{La}$ famosa decadencia: una selección de Azorín (《著名的衰落: 阿左林小品集》) (2018) acaba de ser publicado, su influencia queda por probarse con el tiempo. (Sang Nong 2018, 21 de marzo) ${ }^{22}$
\end{abstract}

Cabe preguntarse, ¿cómo se realiza una traducción adecuada? Bien se puede reflexionar que la actividad translativa se vincula estrechamente con la creatividad artística propia. ${ }^{23}$ Lo mismo advierte Octavio Paz cuando comenta que

\footnotetext{
${ }^{21}$ Sang Nong (2018, 21 de marzo): 《又见阿索林》/ «Encontrar a Azorín de nuevo». 中华读书报 / Diario Lectura Zhonghua. Véase en: <https://epaper.gmw.cn/zhdsb/html/201803/21/nw.D110000zhdsb_20180321_2-11.htm?div=-1> [Consulta: 30 de agosto de 2021].

${ }^{22}$ La traducción es mía.

${ }^{23}$ Croce llama producción a la traducción («not reproduction, but production») (López García 1996: 393).
} 
el texto original jamás reaparece (sería imposible) en la otra lengua; no obstante, está presente siempre porque la traducción, sin decirlo, lo menciona constantemente o lo convierte en un objeto verbal que, aunque distinto, lo reproduce: metonimia o metáfora. Octavio Paz (1971: 10)

O cuando advierte de que la traducción es indistinguible muchas veces de la creación» (Octavio Paz 1971: 16). Para Benjamín (1996: 338), «la finalidad de la traducción se halla, en definitiva, en la expresión de la correlación intrínseca entre las lenguas».

Dado que el lenguaje que aplica Azorín en sus ensayos conlleva ciertos elementos líricos, en comentario de Baquero Goyanes,

existen en la prosa de Azorín abundantes elementos rítmicos, aunque manejados siempre con tal arte y delicadeza que su sonoridad no rompe la suave armonía de la que cabría definir como prosa dicha en voz baja. (apud Martínez Cachero 2018: 53)

$\mathrm{Y}$ «muchos de los mejores poemas de cada lengua de Occidente son traducciones y que muchas de esas traducciones son obra de grandes poetas» (Paz 1971: 10). En conformidad con estas apreciaciones, las traducciones de Dai Wangshu, Xu Xiacun y Bian Zhilin nos resultan especialmente interesantes por el instinto profundo que muestran, que recupera al poeta consagrado y al escritor eminente, lo que aseguró el éxito de Azorín en China. Lin Yian, traductor de Azorín de la versión de 2018, manifiesta en el prólogo que:

¡Sin embargo, los tres Dai, Xu y Bian capturaron el estilo de Azorín de una vez! Al leer su traducción, parece que estoy leyendo a Azorín. Dado que todos están traducidos del francés o del inglés, puede que no sea difícil de encontrar errores, deficiencias o malentendidos en comparación con los textos originales. Sin embargo, para ser justos, después de más de 80 años, todavía podemos sentir el encanto de su traducción. (Lin 2018: $4)^{24}$

Zhao Lihong (赵丽宏), escritor, ensayista, poeta reputado de nuestra época, dedicó un ensayo titulado «Ver al viejo amigo de nuevo: relectura de Compilaciones de la ventana oeste» (《又见故人来一一重读〈西窗集〉》) (2019), donde se manifiesta lleno de gozo por haber leído la traducción de Azorín realizada por Bian Zhilin hace 20 años. Aunque tantos años pasaran, la relectura le resultó igualmente grata y sorprendente:

Se reúnen textos de varios escritores en el libro, que parecen no haberse convertido en estrellas en China. No obstante, creo que merece la pena leerlos, como con el caso de Azorín de España. Azorín es un escritor muy singular, ha escrito muchas novelas y unas cortas colecciones de ensayos. Sus logros literarios se reflejan principalmente en la prosa. Retrata con calma a sus personajes familiares y cuenta su historia con una atmósfera extraña y un poco misteriosa. Ese tipo de compostura y elegancia rara vez se ve en los escritos de los autores de hoy. Además de la prosa, también se incluyen en las obras fragmentos de varias de sus novelas. Lo extraño es que estos fragmentos de novelas no hacen que la gente sienta

${ }^{24}$ La traducción es mía. 
que lee algo abrupto e incompleto, aunque muestren poca coherencia al ser capítulos de prosas separadas. Lo que persiguen las novelas de Azorín no es lo extraño y el suspense de una historia, sino la búsqueda de una atmósfera romántica. Aparte de Compilaciones de la ventana oeste, solo he visto otra traducción al chino de la prosa de Azorín: Paisaje de España (llamada La novia de Cervantes en los años 30 del siglo xx). Se puede observar cómo en la década de 1930 la creación de Azorín atrajo a un grupo de poetas y escritores jóvenes y talentosos en China. Las palabras de Azorín tienen un ritmo musical, incluso desde la traducción al chino, aún se puede sentir el ritmo distintivo. ${ }^{25}$ (Zhao Lihong 2019: 247)

Azorín es «uno de los más elegantes artesanos de nuestra lengua (española)», según palabras de Mario Vargas Llosa (1996: 12); para Ortega y Gasset (2016: 245), sus escritores son «primores de lo vulgar» y para Pío Baroja (1917) es «un maestro del lenguaje». Su talento estético ha influido en una veintena de autores chinos reconocidos. Entre ellos, varios eran amigos de Bian Zhilin, quien, según él mismo manifestaba, llevaba publicando sus traducciones en la revista 《大公报 - 文艺》 (El público. Arte y literatura) entre los años $30 \mathrm{y}$ principios de los años 40, hasta que pudo encontrarse una salida de publicación en formato de libro en 1942. También publicaba allí la escritora Lin Huiyin (林徽因), que leyó los textos de Azorín y se sintió muy interesada por el autor, hasta recordar años después aquellos escritos y valorando a Azorín como a un escritor al que apreciar (Bian Zhilin 2002: 183). En un texto laudatorio de Bian, «He Qifang y Trabajo» (《何其芳与〈工作〉》), señalaba que

hay una influencia que pocas personas parecen notar, y es que la prosa española de Azorín realmente influyó en Dai Wangshu y en He Qifang (especialmente influyó su prosa escrita en la primera mitad de la década de 1930), ${ }^{26}$ e incluso en mí. (Bian Zhilin 2002: 293)

En otros amigos de Bian, como el escritor Li Guangtian (李广田) y el escritor Shi Tuo (师陀), también se encuentran sombras azorinianas. Por ejemplo, se observan en los relatos «El señor cartero» (《邮差先生》) y «El señor lector» (《说书人》) de Shi Tuo (师陀).

\section{AZORÍN Y WANG ZENGQI}

De la influencia del alcance de Azorín en China, de entre los testimonios de adhesión a su obra, cabe destacar al escritor Wang Zengqi (汪曾祺 1920-1997), quien declaró: «Azorín es un escritor al que he adorado durante toda mi vida» ${ }^{27}$ (Wang Zengqi 1998: 14). Como fuente de inspiración más notoria, Azorín le iluminó desde sus inicios en la carrera de escritor. Le leyó siendo solo un estudiante de segundo año de la carrera de Literatura en la Universidad Asociada

\footnotetext{
${ }^{25}$ La traducción es mía.

${ }^{26}$ Admitió He Qifang (1940: 1426) en su «Una carta a Aiqing: He Qifang habla de Dibujar sueños y mi camino» (《给艾青先生的一封信一一何其芳谈〈画梦录〉和我的道路》) que recibió influencia de Azorín, donde también mencionó la influencia de Pío Baroja.

${ }^{27}$ La traducción es mía.
} 
de Suroeste (西南联大) en 1940, y, fue tal su admiración que acabó escribiendo varios relatos imitando el estilo del autor español. Esto queda reflejado en su ensayo «Sobre el estilo» (《谈风格》), donde explica que son tres etapas por las que se transita para que un escritor establezca su propio estilo: primero, imitar; segundo, deshacerse de la imitación; tercero, convertirse en uno mismo (Wang Zengqi 2016: 3):

Un escritor lee muchos libros, pero, a menudo, son solo unos pocos escritores y unas pocas obras las que realmente pueden influenciar en su estilo. Alguien me preguntó qué escritores me han influido más. Lo pensé detenidamente y de los antepasados debe ser Gui Youguang (归有光). De los escritores chinos modernos destacaría a Lu Xun, a Shen Congwen (沈从文) y a Fei Ming (废名); y de los escritores extranjeros, a Chéjov y a Azorín. (Wang Zengqi 2016: 307)28

Con respecto a Azorín, nos deja en el mismo ensayo el siguiente comentario:

Azorín es raro (este es el título de su propio ensayo). Es un escritor contemplativo, evocador y observador. Es particularmente bueno para describir la tranquilidad, describir la psicología de los personajes en recuerdos silenciosos, en cambios sutiles. El drama de sus novelas es indetectable. Su «corriente de conciencia» es clara, cubierta de sombras frías, no es desordenada y caótica. Muestra entusiasmo tranquilamente y en mundos aislados. La España descrita por Azorín es una España vieja, y una España auténtica. (Wang Zengqi 2016: 311 $)^{29}$

Lo que percibe Wang Zengqi sobre el estilo de Azorín es muy certero, a pesar de que su recepción fuese a través de las repetitivas lecturas de las traducciones indirectas de Dai Wangshu, Xu Xiacun y de Bian Zhilin. Precisamente, en su ensayo «Azorín es raro: lectura de "La novia de Cervantes"» (《阿索林是古怪的一一读阿索林的〈塞万提斯的未婚妻〉》) Wang Zengqi analiza el citado relato de Azorín, comentando que es un relato extraño, estructuralmente carente de regla alguna, el tono que emplea es humorístico y la España que describe está en un ambiente melancólico, llena de elementos de «lo castizo», de recuerdos, del aliento de Cervantes. Asimismo, afirma que el Cervantes de Azorín es el verdadero Cervantes, un poeta amable que le habla a su prometida de manera simple, ordinaria, más grande que todas las palabras de su libro (Wang Zengqi 1998: 14). La temática fundamental de Azorín es la interpretación de Castilla, descubriendo las costumbres y la psicología de sus habitantes: «Se medita sobre el paisaje o pueblo como 'pequeña' historia transida por el tiempo» (Fox 2014: 11). En palabras de Ortega y Gasset:

En Azorín no hay nada solemne, majestuoso, altisonante. Su arte se insinúa hasta aquel estrato profundo de nuestro ánimo donde habitan estas menudas emociones tornasoladas. No le interesan las grandes líneas que, mirada la trayectoria del hombre en sintética visión, se desarrollan serenas, simples y magníficas, como el perfil de una serranía. Es todo lo

${ }^{28}$ La traducción es mía.

${ }^{29}$ La traducción es mía. 
contrario de un «filósofo de la historia». Por una genial inversión de la perspectiva, lo minúsculo, lo atómico, ocupa el primer rango en su panorama, y lo grande, lo monumental, queda reducido a un breve ornamento. (Ortega y Gasset 2016: 248)

Así, nos encontramos en el «El apañador», «La vida de un labrantín», «Un trasnochador», «una ciudad», «La piedra gris», «El melcochero», etc., a personas comunes y objetos ordinarios. Azorín fue autor de más de cuatrocientos cuentos y confesaba en un artículo de $A B C$ de 1944 que

\begin{abstract}
después de escribir tantos cuentos, he llegado a la conclusión de que el verdadero cuento, el más artístico, es que el cuentista forja con una minucia; el cuento con argumento de cierta truculencia está al alcance de todos. Naturalmente que la minucia de que se trate ha de ser cosa delicada. (apud Baquero Goyanes 2010)
\end{abstract}

Para Vargas Llosa, Azorín es un escritor miniaturista:

En verdad, era un miniaturista, como esos que pintan paisajes en la cabeza de un alfiler o que construyen barcos con palitos de fósforos en el interior de una botella. Tenía predilección por lo desdeñado y secundario, por lo que rara vez atrae la atención o se olvida de inmediato, por los seres anodinos y las cosas insignificantes. En sus descripciones, que eran invenciones, los pequeños objetos alcanzan a veces una extraordinaria dignidad. (Vargas Llosa 1996: 26)

Wang Zengqi se sentía heredero de esta inversión de la perspectiva de lo minúsculo. En él desaparece los grandes hombres, los magnos acontecimientos, insertándose en sus escritos los detalles de la vida cotidiana más pura de los chinos, mostrando, asimismo, la esencia de la tradición. En realidad, un árbol, una fruta, una flor, una comida, un insecto, etc., cualquier cosa puede convertirse en su temática de escritura. En él, el tiempo transcurre lento, como a cámara lenta, se oye el viento, el sonido de la respiración, se alienta un abanico de gentes comunes, de objetos humildes, materia insignificante a menudo, tal como se recoge en relatos como «Las señoras» (《大妈们》), «Comer» (《吃饭》), «Sobre uvas» (《关于葡萄》), «La lluvia de Kunming» (《昆明的雨》), «Los insectos de verano» (《夏天的昆虫》), 《Los platos de Kunming》 (《昆明菜》), etc.

Si bien en Azorín se advierte su esfuerzo e intención de reconstruir una cultura ética y espiritual para salvar a su país de la decadencia, esta preocupación ideológica no se halla ciertamente en Wang Zengqi, que carece de los problemas nacionales y de las inquietudes sociales del autor alicantino. Su intención es meramente la de meditar sobre el paisaje, la vida cotidiana, la tradición, las costumbres, la psicología de los habitantes, fijándose en los detalles del mundo que le rodea para manifestar el interés y la curiosidad de la vida.

La impronta queda evidenciada no solo en la inversión de perspectiva, es decir, en la narración de la microhistoria, sino también se encuentra en la forma y en el estilo. Azorín se caracteriza por el uso de frases cortas, de sintaxis simple: «En él es esencial la brevedad. Cuando se alarga, generalmente se esfuma» (Vargas Llosa 1996: 24). También destaca por el uso de dos o tres adjetivos unidos 
(ej. «Todos son menuditos, rubios o morenos, con sus melenas cortas y sedosas, con sus mejillas encendidas», Azorín 1919: 30), o por una enumeración de sustantivos (ej. «Hay calles que se llaman: de las Dueñas, las Angustias, Boteros, Tenerías, Colegio Viejo, la Encomienda, la Puerta Rota, Bachilleres, Pan y Carbón, Tahonas Viejas, Bermejeros, Donados, Labrador Chico, Azorín 1920: 151), por una serie de acciones (ej. «En el entretanto, él sale al campo, labra, cava, poda los árboles, escarda, bina, estercola, cohecha, sacha, siega, trilla, rodriga los majuelos y las hortalizas, escarza tres o cuatro colmenas que posee», Azorín 1920: 116), en el uso de la enumeración ( $\mathrm{Su}$ cuarto es una buhardilla con tragaluz. En la buhardilla hay una mesa, una cama, un armario, un lavabo, dos o tres sillas y un estante de libros», Azorín 1920: 169; «Va a partir el tren; en mi coche sube una señora enlutada; suben también con ella dos chicos, tres chicos, cuatro chicos, seis chicos», Azorín 1919: 30), ${ }^{30}$ etc., produciendo un ritmo lírico, que en palabras de Vargas Llosa (1996: 22) es «lo que les da el semblante de poemas en prosa». En verdad, es capaz de convertir lo vulgar en primor, y

'Primores de lo vulgar' tituló Ortega y Gasset el ensayo que le dedicó. En el contraste de ambos conceptos está perfectamente resumido el arte azoriniano, hecho de menudencias, minucias, inanidades e insignificancias, que, gracias a la pulcritud del estilo, la sutileza de la observación y la audacia de la estructura se vuelven objetos merecedores de reverencia y cariño. (Vargas Llosa 1996: 24).

El eco de Azorín resuena con fuerza en muchos textos de Wang Zengqi a través de este tipo de enumeraciones de conceptos cotidianos según presentamos en los ejemplos siguientes: ${ }^{31}$

老刘说, 坝上地大, 风大, 雪大, 雹子也大。(Wang Zengqi 2020: 15)

['El señor Liu dice que en el dique la tierra es grande, el viento grande, la nieve grande, el granizo también es grande']

教员一人一宿舍, 室内床一、桌一、椅一。(Wang Zengqi 2020: 25)

['Los maestros viven en dormitorios individuales, dentro hay una cama, una mesa, una silla']

我们的生活很清简。教书、看书。打桥牌, 聊大天。吃野菜, 吃灰菜、野苋菜。(Wang

Zengqi 2020: 27)

['Vivimos una vida muy simple. Enseñar, leer. Jugar a las cartas, chatear. Comer verduras silvestres, comer cenizo, comer amaranto tricolor silvestre']

她每天不断地擦、洗、掸、扫。(Wang Zengqi 2020: 39)

[‘Ella limpia, lava, desempolva, barre todos los días sin parar']

小邱给她买了很多东西: 衣服、料子、鞋、头巾 (Wang Zengqi 2020: 38)

['Xiao Qiu le compró muchas cosas: ropa, tela, zapatos, pañuelo...']

\footnotetext{
${ }^{30}$ Todos los ejemplos seleccionados son de Los pueblos y España. Hombres y paisajes. Hemos de destacar que estas características del estético del lenguaje azoriniano son bien reproducidas en la traducción de Dai, Xu y Bian.

${ }^{31}$ Las traducciones son mías.
} 
En resumidas cuentas, Azorín influye en Wang Zengqi a través de la fijación de la perspectiva de una microscópica agudeza, en la manera de ver el mundo.

\section{CONCLUSIÓN}

Vivió Azorín noventa y cuatro años y buena parte de su vida la dedicó a enriquecer la vida de las gentes comunes, embelleciéndoles en sus creaciones literarias con "primores de lo vulgar». Su cultivo de un estilo distintivo ha iluminado a muchos escritores y lectores españoles, e, indudablemente, la traducción le ha llevado a lares más lejanos, convirtiéndose en un escritor universal e inmortal. Desde que llegó en la década treinta del siglo pasado a China, Azorín radica en esta tierra lejana y se sigue leyendo, renovando y reviviendo por la aparición de nuevas ediciones, traducciones, comentarios e imitaciones.

Ciertamente, todavía quedan muchos trabajos de traducción que realizar, incluidas obras tan importantes como la trilogía autobiográfica de La Voluntad (1902), como Antonio Azorín (1903) y como Las confesiones de un pequeño filósofo (1904). Por supuesto, quedan pendientes también las revisiones y correcciones sobre las primeras traducciones, que eran de carácter indirecto, como hemos comentado, aunque no exentas de calidad literaria.

Como puede comprobar el lector, Azorín ha tenido un éxito duradero en China. Desde que se leyó en esta tierra, siempre ha sido un escritor admirado y se le ha mostrado un cariño verdadero. Sus libros han estimulado y emocionado a tantos lectores que, realmente, se ha llegado a producir un intercambio literario de influencias factuales. Su visión del mundo, su perspectiva y su estilo literario verdaderamente han traspasado las fronteras nacionales, llegándose a considerar un factor importante en la construcción de la literatura china moderna. Sin duda, como investigadores, nos enfrentamos a muchas posibilidades tanto en la investigación de la traducción de la obra de Azorín como en los estudios en el campo de la Literatura comparada.

Finalmente, para terminar, nos es grato recoger aquí las siguientes palabras de Azorín para comprobar cómo se engañaba él mismo:

EQUIS. $-i Y$ a usted no le conviene que le traduzcan?

ZEDA. -No suelo contestar las cartas en que se me piden autorizaciones. No creo que mis libros puedan interesar en el extranjero; en el extranjero en que no se hable castellano.

EQUIS. -¡Pesimismo! ¡Misantropía! ¡Displicencia!

ZEDA. -No; verdad. Mis libros son demasiado españoles, si es que son algo.

EQUIS. -Por eso de que son españoles, de que son demasiado españoles, pueden interesar. ZEDA. -El ser demasiado español, en este caso, es recoger lo íntimo de lo español; el matiz sutil, imponderable. Y eso se evapora al pasar de una lengua a otra... (apud Navarro Domínguez 2015: 11) 


\section{BIBLIOGRAFÍA}

AZORÍN (1919), Los pueblos. Ensayos sobre la vida provinciana, Madrid, Rafael Caro Raggio (Obras completas, tomo VI).

AzORÍN (1920), España. Hombres y paisajes, Madrid, Rafael Caro Raggio (Obras completas, tomo $\mathrm{V})$

AZORín (1982)，西班牙小景, Fuzhou, Editorial Pueblo de Fujian. (trad. de Dai, W. S. / 戴 望舒 y Xu, X. C. / 徐霞村, Paisaje de España)

AzORÍN (2013), 塞万提斯的未婚妻, Beijing, Joint Publishing Company. (trad. de Dai, W. S. / 戴望舒, La Novia de Cervantes)

Azorín (2014), Castilla, Barcelona, Austral.

AZORÍN (2017), Madrid, Madrid, Biblioteca Nueva.

AZORÍN (2018a), 著名的衰落：阿左林小品集, Guanzhou, Editorial Huacheng. (trad. de Lin Yian / 林一安, La famosa decadencia: una selección de Azorín)

AZORÍN (2018b), La ruta de don Quijote, Madrid, Cátedra.

BAQUERO GOYANES, M. (1968), «Los cuentos de Azorín», Edición digital a partir de Cuadernos Hispanoamericanos, 226-227, 355-374. Disponible en: $<$ http://www.cervantesvirtual.com/obra-visor/los-cuentos-de-azorin/html/d537f aac-369b-41fa-9164-e1832820e175_2.html>.

BENJAMIN, W. (1996), «La tarea del traductor (traducción de Hans Christian Hagedorn)», en Teorías de la traducción. Antología de textos, López García, D. (ed.), Cuenca, Ediciones de la Universidad de Castilla-La Mancha, 335-347.

BIAN, Z. L. / 市之琳 (2002)，六之琳文集.中卷/ Obras de Bian Zhilin, vol. 2, Hefei, Editorial Educación Anhui.

BIAN, Z. L. / 市之琳 (1982), 西窗集 / Compilaciones de la ventana oeste, Nanchang, Editorial Jiangxi.

DAI, W. S. / 戴望舒 (1999), 戴望舒全集·散文卷/ Obras completas de Dai Wangshu. Volumen de ensayos, Beijing, Editorial Jóvenes de China.

FISAC, T. (2017), «¿Puede la cultura europea inspirar a los escritores chinos?», Revista de Occidente, 430, 47-60.

FOX, E. I. (2014), «Introducción», en Azorín. Castilla, Barcelona, Austral, 11-89.

GIL-ALbARELlOS, S. (2006), Introducción a la literatura comparada, Valladolid, Ediciones Universidad de Valladolid.

GUILLÉN, C. (2005), Entre lo uno y lo diverso: introducción a la literatura comparada (ayer y hoy), Barcelona, Tusquets Editores.

HE, Q. F. / 何其芳 (1940)，给艾青先生的一封信一一何其芳谈〈画梦录〉和我的道路》 / «Una carta a Aiqing: He Qifang habla de Dibujar sueño y mi camino», 文艺阵地 I Espacio de Literatura y arte, 4(7), 1421-1432.

JURETSCHKE, H. (1998), «La recepción de la Generación del 98 en Europa en la primera mitad de nuestro siglo», en La traducción en torno al 98, Vega Cernuda, M. Á. (ed.), Madrid, Instituto Universitario de Lenguas Modernas y Traductores, 53-64.

LIN, Y. A. / 林一安 (2018), «Prólogo», en Azorín. 著名的衰落：阿左林小品集, Guanzhou, Editorial Huacheng, 1-8. (trad. de Lin, Y. A. / 林一安, La decadencia célebre: una selección de Azorín)

LOZANO, M. Á. (2015), "Azorín y Miró en la Literatura Española», en Azorín y Miró en traducción, Navarro Domínguez, F. (ed.), Alicante, Publicaciones de la Universidad de Alicante, 13-30. 
MARTínez CACHERO, J. M. (2018), «Introducción», en Azorín. La ruta de don Quijote, Madrid, Cátedra, 9-71.

ORTEGA Y GASSET, J. (2016), El espectador I y II, Madrid, Alianza Editorial.

PAYA, J. (2015), «China descubre la obra de Azorín» [en línea]. Alicante: Levante, 26 de marzo de 2015 [Consulta: septiembre 2021]. Disponible en: <https://www.levanteemv.com/cultura/2015/03/26/china-descubre-obra-azorin-12602872.html>.

PAZ, O. (1971), Traducción: literatura y literalidad, Barcelona, Tusquets, 7-20.

PRADO-FONTS, C. (2008), «El nacimiento de la literatura moderna», en Narrativas chinas. Ficciones y otras formas de no-literatura, Martínez Robles, D., Prado-Fonts, C. y Relinque Eleta, A. (eds.), Barcelona, Editorial Uoc, 117-167.

PRADO, Á. (2013), «Azorín viaja a China» [en línea]. Alicante: Información, 14 de abril de 2013 [Consulta: septiembre 2021]. Disponible en: $<$ https://www.informacion.es/cultura/2013/04/14/azorin-viaja-china-6652941.h tml>.

QIAN, L. Q. (1994), «The eastward journey of Don Quijote and Hamlet», en Chinese Literature and European Context, Gálik, M. (ed.), Bratislava, Institute of Asian and African Studies of the Slovak Academy of Sciences, 99-104.

SANG, N. / 桑农 (2018), 《又见阿索林》/ «Ver a Azorín de nuevo»中华读书报/ Diario Lectura Zhonghua, 21 de marzo de 2018, 11. Disponible en: https://epaper.gmw.cn/zhdsb/html/2018-03/21/nw.D110000zhdsb_20180321_2-

11.htm?div=-1 [último acceso: septiembre 2021].

SANG, N. / 桑农 (2013), «Prólogo», en Azorín, 塞万提斯的未婚妻 / La Novia de Cervantes, Sang, N. (ed.), Beijing, Joint Publishing Company, 1-3. (trad. de Dai W. S. / 戴望舒 ) .

TANG, T. / 唐㢷 (2013), «阿索林 / Azorín», en Azorín, 塞万提斯的未婚妻 / La Novia de Cervantes, Sang, N. (ed.), Beijing, Joint Publishing Company, 199-200. (trad. de Dai W.S. / 戴望舒)

VARGAS LlOSA, M. (1996), Las discretas ficciones de Azorín, Barcelona, Real Academia Española.

WANG, Z. Q. / 汪曾祺 (2020), 人生有趣 / La vida es interesante, Tianjin, Editorial Población de Tianjin.

WANG, Z. Q. / 汪曾祺 (2016)，说说唱唱 / Hablar y cantar, Beijing, Editorial Escritores.

WANG, Z. Q. / 汪曾祺 (1998), 汪曾祺全集 (第六卷) / Obras completas de Wang Zengqi, vol. 6., Beijing, Editorial Universidad Normal de Beijing.

XU, C. H. / 徐曾惠 y FAN, R. H. / 樊瑞华 (1988), 卡斯蒂利亚的花园/ El jardin castellano, Beijing, Editorial Escritores 1988.

XU, X. C. / 徐霞村 (1930), 现代南欧文学概观 / Panorama de la literatura moderna de Europa Meridional, Editorial Shenzhou Guoguang.

ZHAO, L. H. / 赵丽宏 (2019), 《又见故人来一一重读〈西窗集〉/ Ver al viejo amigo de nuevo: relectura de Compilaciones de la ventana oeste», en 遥远的叹息/ Suspiro lejano, Zhao, L. H. / 赵丽宏 (ed.), Shanghái, Editorial Este, 243-251.

ZHOU, Z. R. / 周作人 (2002), «西班牙的古城 / La ciudad antigua de España», en 看云集 / Colección de mira las nubes, Zhou, Z. R. (ed.), Shijiazhuang, Editorial Educación Hebei, 116-118. 